\title{
VICTOR LEAL E O ROMANCE-FOLHETIM NO RIO DE JANEIRO NO FINAL SÉCULO XIX
}

\author{
Leonardo Mendes (UERJ) \\ leop@cruiser.com.br \\ Andréa Gonçalves da Silva (UERJ)
}

O romance-folhetim surgiu na França na primeira metade do século XIX e logo ganhou lugar de destaque no jornal francês. O aparecimento do gênero estava ligado ao processo de popularização da imprensa e da literatura que vemos ocorrer no período. Como explica José Ramos Tinhorão (1994, p. 7):

O aparecimento na França das histórias escritas para a publicação em capítulos, em rodapés de jornal, coincidiu em meados da década de $1830 \mathrm{com}$ a tendência a democratização revelada pela imprensa monárquica de julho, sob o governo de Luís Felipe, quando as massas populares de Paris começaram a forçar sua participação política, através de uma inquietação logo traduzida na série de teorias de reforma social tão características do século XIX.

O folhetim chega ao Brasil no final do século XIX, carregado de características formais inovadoras que tornam seu enredo melodramático, divertido e atraente. Mais do que um gênero, o folhetim deve ser pensado como um lugar de inovação e experimentação da imprensa diária, como um "vale-tudo", na expressão de Marlyse Meyer:

Aquele espaço vale-tudo suscita todas as formas e modalidades de diversão escrita: nele se contam piadas, se fala de crimes e de monstros, se propõe charadas, se oferecem receitas de cozinha ou de beleza; aberto às novidades, nele se criticam as últimas peças, os livros recém-saídos - o esboço do Caderno $B$, em suma. E numa época em que a ficção está na crista da onda, é o espaço onde se pode treinar a narrativa, onde se aceitam mestres e noviços do gênero, histórias curtas ou menos curtas e adota-se a moda inglesa de publicações em série se houver mais textos e colunas (1996, p. 58).

O grande sucesso de público do folhetim devia-se ao fato, entre outros, de ser uma forma de literatura que surpreendia o leitor com mui- 
tos recursos técnicos tomados emprestados à tradição da literatura popular, tais como cortes bruscos, redundâncias, finais inesperados, além de heranças da literatura gótica, consolidando suas características principais. A atmosfera misteriosa de aflição e suspense prendia o leitor até o desfecho da trama.

Como o romance-folhetim era publicado diariamente num fluxo de tempo real, com forte investimento no presente, na trama poderiam surgir personagens inesperados, digressões, desvios e voltas ao fio condutor, resultando numa movimentação constante da ação. Se um personagem não estivesse agradando ao público, ele poderia morrer repentinamente ou desaparecer misteriosamente, redimensionando desse modo as noções tradicionais de verossimilhança. Desse ponto de vista, o romance-folhetim mais típico antecipa o conceito de obra aberta (ECO, 2001). A trama era construída no dia-a-dia, sob a interferência das cartas de leitores a Gazeta e a outros jornais, no caso do Brasil.

Na década de 1960, surge a mais avançada concretização do folhetim: a novela de televisão: uma história que parte de uma simples proposta de tema geral, e escrita posteriormente, capítulo a capítulo, muitas vezes a várias mãos, sujeito às reações do público e aos interesses dos veículos de divulgação.

Como vimos, o espaço do rodapé do jornal servia para crônicas, artigos, contos, anúncios, fofocas e casos policiais. De fato, na edição do primeiro capítulo do folhetim Paula Mattos ou o Monte Socorro, na Gazeta de Notícias, a ficção aparecia lado a lado de crônicas policiais, mostrando como o alvo do gênero era o leitor popular, com apetite para emoções fortes.

O folhetim era um espaço diversificado do jornal diário onde cabia tudo e essa indefinição quase sempre foi avaliada pela tradição crítica como um defeito. José Ramos Tinhorão, por exemplo, fala em literatura "rebaixada" ao se referir ao folhetim, estabelecendo uma clara hierarquia entre gêneros nobres e vulgares, que retira capital simbólico tanto dessa forma de literatura como de seus praticantes:

Essa diluição dos nobres conceitos de valorização do indivíduo, da emoção e da liberdade do romantismo burguês, ia ser conseguida na prática para atender ao gosto rebaixado da pequena burguesia que não lia livros, mas comprava jornais (TINHORÃO, 1994, p. 40, grifos nossos). 


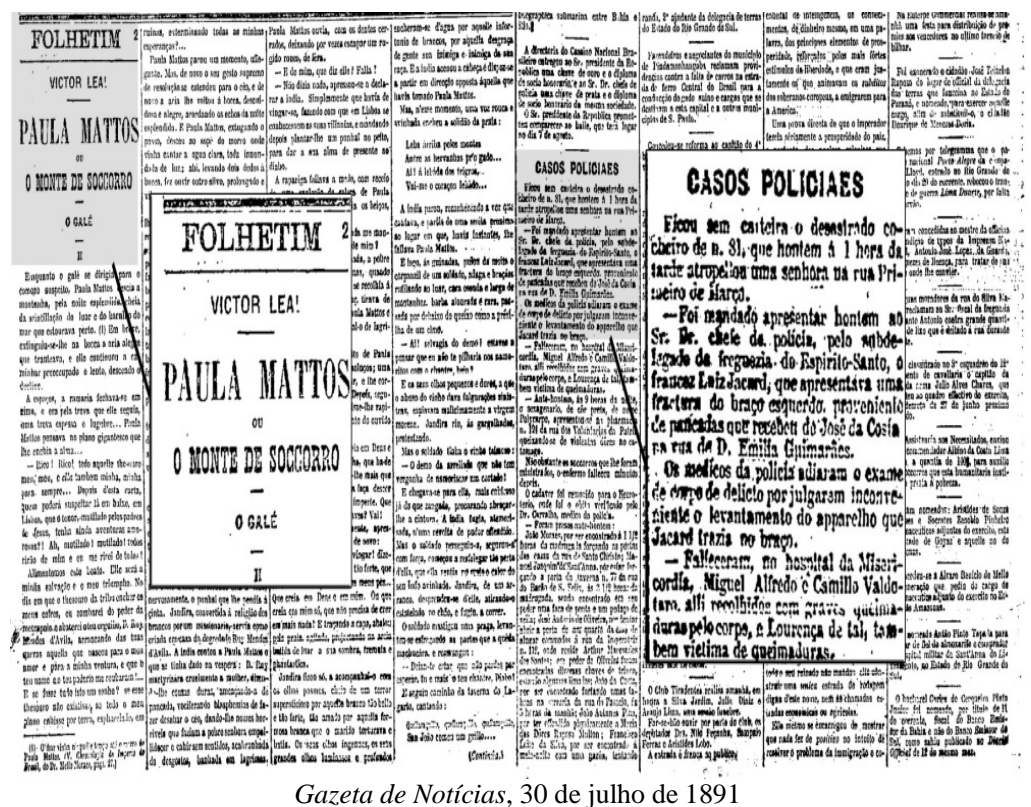

Com o tempo, o folhetim deixa de ser apenas um local nas páginas dos jornais e passa a designar uma forma especifica de literatura. $\mathrm{O}$ lugar de publicação dá o nome ao gênero que o ocupa: o romancefolhetim. Entretanto, devido à sua falta de prestígio entre as camadas letradas, alguns escritores usavam pseudônimos para preservar suas imagens de escritores "sérios". Desta forma o escritor poderia preservar seu estilo e leitores cultos, e ao mesmo tempo cultivar outro público leitor mais popular, com uma prática mais rentável de escrita. Esse foi o caso de Aluísio Azevedo, que supunha o folhetim uma forma de arte inferior ao romance naturalista, que era sua escola de preferência (BROCA, 2000; MÉRIAN, 1988).

Um exemplo dessa prática é o folhetim Paula Matos ou O Monte de Socorro, de Victor Leal, um nome que na verdade reunia um grupo de escritores praticantes de outros estilos e gêneros: o romancista naturalista Aluísio Azevedo (1857-1913), o poeta parnasiano Olavo Bilac (18651918), o prolífico romancista Coelho Neto (1864-1934), de difícil classificação, e jornalista e romancista João Carlos de Medeiros Pardal Mallet (1864-1894). 
Publicado na Gazeta de Notícias, no Rio de Janeiro, do dia 30 de julho ao dia 14 de agosto de 1891, Paula Mattos ou o Monte Socorro é um folhetim que foi recuperado para leitura e estudo por meio de consulta ao microfilme depositado na Biblioteca Nacional, sob o patrocínio da Fundação de Amparo à Pesquisa do Estado do Rio de Janeiro (FAPERJ), na modalidade de bolsa PIBIC do projeto de pesquisa "Pequenos épicos: o romance-folhetim no Rio de Janeiro no final do século XIX", desenvolvido no Departamento de Letras da Faculdade de Formação de Professores da UERJ.

O interesse por ele se deve, em primeiro lugar, a seu ineditismo. Ao contrário dos outros três folhetins atribuídos a Victor Leal - O Esqueleto (1890) e A Mortalha de Alzira (1891) -, Paula Mattos é o único que permanece inédito em formato de livro. Além disso, ele é o único em que Victor Leal reúne quatro grandes escritores reconhecidos da tradição literária brasileira. Enquanto em $O$ Esqueleto, Victor Leal tinha sido Bilac e Pardal Mallet, em A Mortalha de Alzira Aluísio Azevedo assumiria sozinho o pseudônimo. Paula Mattos ou O Monte de Socorro é, portanto, a única das três obras em que Victor Leal escreve a oito mãos.

Ele conta a história de Paula Mattos, um Chantre de El'Rei, que vive em busca de dois grandes objetivos: encontrar o ouro escondido no Monte de Socorro e salvar sua amada Catharina, que é casada com o D. Ruy D’Ávila. Temos aqui o tema do tesouro escondido, próprio do romance popular de aventuras, unido à trama da donzela raptada, típica do melodrama (THOMASSEAU, 2005). No desenrolar da trama surgem mistérios tenebrosos, emergem segredos do passado, atravessam-se ruínas e passagens secretas, manuscritos escondidos são revelados, maldições são lançadas, conspirações são tramadas, confrontos sangrentos se armam entre personagens rocambolescos, com uso inflacionado de recursos que pudessem manter viva a trama, de modo a garantir a fidelidade do leitor e a venda dos jornais.

$\mathrm{Na}$ trama ganha destaque o personagem Sebastião, que também atendia pelo nome terrível de "Trinca-entranhas" e ainda pelo título nobre de Conde de Santa Maria de Riba Mar, marcando uma identidade em fluxo própria do enredo rocambolesco (MEYER, 1998). Ele surge como um soldado beberrão e atrapalhado, mas logo se torna servo fiel de Paula Mattos. Nessa capacidade, revela-se o terrível trinca-entranhas, esperto e muito valente. Entretanto assim que é revelado seu segredo do passado e o motivo de sua sede de vingança, Sebastião transforma-se no poderoso Conde de Santa Maria de Riba Mar, conhecedor de passagens secretas e 
temido por seus servos, que surgem do nada e da mesma forma desaparecem. Toda a trama passa então a girar em torno da vingança do Conde de Santa Maria De Riba Mar. O objetivo de Paula Mattos de recuperar sua amada Catharina e encontrar o ouro para que pudessem viver felizes e ricos no Brasil, passa, então, para segundo plano. Tal mudança de foco era típica de uma narrativa escrita dia a dia, redirecionando as energias narrativas para núcleos que se revelassem com mais potencial melodramático (MEYER, 1996).

$\mathrm{Na}$ narrativa, um local importante de encontros e peripécias é a "Covanca do Lagarto". Lá acontece de tudo: desde brigas entre bêbados até revelações de segredos mortais e juras de vingança a preço da própria vida. Além disso, a Covanca do Lagarto é um ponto de ligação entre todos os lugares da narrativa: "Fronteira ao monte juntamente... sem luz... em noites calmas... abre de suas portas a alocada de Simão Carola, ...o chamado a Covanca do Lagarto". ${ }^{20}$ Lá aparecem fossos por baixo de tapetes, túneis subterrâneos atrás de portas secretas e quartos malassombrados:

E levantou a folha de um alçapão, depois de afastar rapidamente um velho estrado que havia em cima. E debruçando-se sobre o esvaziamento do escuro subterrâneo, meteu dois dedos na boca e silvou um sinal.

Surgiram quase com por encanto três homens quase nus, armados de corda.

- Amarrem-no! Ordenou Trinca-entranhas mostrando o chefe de polícia, e vendem-lhe a boca para que não grite!" (Gazeta de Notícias, 3 de agosto de 1891, p. 3).

Simão Carola, o proprietário do estabelecimento, parece ser um subalterno de Paula Mattos enquanto este era o herói da história: "Paula Mattos entrou seguido respeitosamente pelo Carola, que se desmanchava em zumbaias. Atirou o largo feltro sobre o leito, e abancou-se à mesa" (Gazeta de Notícias, 03 de agosto de 1891, p. 3). Entretanto, quando Trinca-entranhas entra em cena, Simão, que o tinha escorraçado anteriormente (quando ele era o Sebastião, soldado atrapalhado e bêbedo), torna-se o mais temente servo de longa data. E isso torna tudo rocambolesco e misterioso, contribuindo para a manutenção do interesse do leitor. Estas são características que estão presentes nas três obras de Victor Leal.

Quando o escritor surgiu, muito se especulou sobre sua identidade e por onde andava, já que não frequentava os teatros e nem as redações

\footnotetext{
${ }^{20}$ Devido à deterioração do documento original, algumas palavras ilegíveis foram substituídas por reticências.
} 


\section{FACULDADE DE FORMAÇÃO DE PROFESSORES}

de jornais na Rua do Ouvidor. Em 15 de março de 1890, dois dias antes da publicação do primeiro fascículo do romance-folhetim $O$ esqueleto, havia sido publicado na primeira página da Gazeta de Notícias um retrato de Victor Leal, desenhado pelo ilustrador Gustavo Hastoy, e isso fez com que o público acreditasse que ele de fato existia. O retrato vinha acompanhado de um texto:

O esqueleto não é propriamente Victor Leal. O rapaz é magro, mas nem tanto. Ontem é que ele nos apareceu, como se tivesse vindo do outro mundo.

Foi o caso, que o homem cuidava a tempos em investigações e estudos profundos sobre um fato dos tempos coloniais, e eis que senão quando um pedreiro, um simples pedreiro, com uma enxada, cavou mais fundo que ele e descobriu o esqueleto no antigo Paço da cidade.

- Estou roubado! Exclamou Victor Leal.

E correu cá para o escritório, e pediu ao Hastoy que lhe tirasse o retrato, antes que o Diário do Comércio venha dizer que foi o primeiro que pensou em escrever um romance sobre o esqueleto ou que ele é o defensor de todos os oprimidos, do comércio, da indústria e dos esqueletos.

Para fazer-lhe a vontade, damos hoje o retrato de Victor Leal, o ilustre literato. Amanhã daremos o esqueleto reproduzido do natural, e depois de amanhã começaremos a publicar o romance (Gazeta de Notícias, 15 de março de 1890).

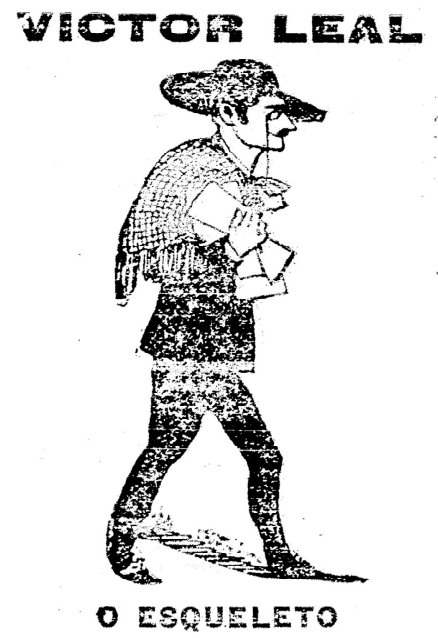

(AI YSTERIOS DA CASA DK BRAGANCA)

o esqueleto náo propriamento Victor

Victor Leal por Gustavo Hastoy, Gazeta de Notícias, 15 de março de 1890 
Nesta ocasião, havia sido encontrado um esqueleto no Paço Imperial e para garantir a autenticidade de sua ideia em escrever um folhetim sobre o fato, foi publicado o retrato de Victor Leal na Gazeta de Notícias. Em 1894, no prefácio de A Mortalha de Alzira, Aluísio Azevedo revelou como tudo aconteceu e quem de fato era (ou eram) Victor Leal.

\begin{abstract}
Ora, eu precisava repousar um pouco o espírito num romance de fantasia, e que, de muito tempo à essa parte, sentia falta de um adversário literário. (...) Aceitei a proposta da Gazeta de Notícias, com a única condição de substituir meu nome pelo pseudônimo de Victor Leal (...). Olavo Bilac e Pardal Mallet tinham já feito, de colaboração e em segredo, uma complicada fantasia intitulada $O$ esqueleto (AZEVEDO, 2000, p. 115).
\end{abstract}

Numa crônica de 17 de outubro de 1893, publicada na Gazeta de Notícias, Olavo Bilac acrescenta que bastava olhar com atenção para o retrato de Victor Leal para descobrir seu segredo: "Havia com efeito nesse retrato os olhos adoráveis de Aluísio Azevedo (os mais belos olhos de homem que conheço, leitora!), a vivacidade felina da fisionomia de Coelho Neto, a pose à d'Artagnan de Pardal Mallet, e o nariz titânico, descomunal, de quem está agora escrevendo essas cousas" (2000, p. 102).

Naquele mesmo prefácio, Aluísio confirma a popularidade de Victor Leal e do romance-folhetim:

Estive quase a ter medo de mim mesmo, quero dizer, de Victor Leal. Se o público quer essa obra e diverte-se com ela, que a leia!

Terei eu o direito de escondê-la?

Não! Não seria digno de um adversário correto! Victor Leal que rejubile vitorioso e vá para o diabo que o carregue ou para os braços dos seus admiradores sentimentais. Eu é que não estou disposto a aturá-lo mais! (AZEVEDO, 2000, p. 119).

No pouco tempo em que escreveu e publicou, Victor Leal ganhou nome, identidade e reconhecimento popular. A leitura de seus três romances revela certas características que o distinguem. Temos, de um lado, o forte investimento na tradição da literatura gótica, com sua preferência por cenários aristocráticos do século XVIII, um mundo em que nobres e seus lacaios cometem crimes executados por trás de passagens secretas ou em tavernas misteriosas, num ambiente de segredo próprio das maçonarias. $\mathrm{O}$ investimento no imaginário da literatura gótica europeia, de forte apelo popular, é visível nos três romances de Victor Leal, e especialmente em A mortalha de Alzira, que se passa na Paris de Luís $\mathrm{XV}$. 


\section{FACULDADE DE FORMAÇÃO DE PROFESSORES}

Por outro lado, os folhetins de Victor Leal eram também um comentário sobre o presente imediato da vida política e cultural no Rio de Janeiro da infância republicana. A monarquia recém-desempossada era um alvo dileto de ataques irônicos e depreciativos, assim como outras estruturas de poder, especialmente a igreja católica, aparecem associadas à opressão e ao obscurantismo. As tramas rocambolescas reforçavam a veia cômica, notadamente em $O$ Esqueleto e Paula Mattos, garantindo o tom de crítica galhofa lançadas a figuras de autoridade da história recente do país. Podemos supor que os leitores entendiam a piada e compravam os jornais para rir de seus governantes.

Tais características nos habilitam a considerar Victor Leal uma espécie de heterônimo de um grupo de jovens escritores brasileiros do final do século XIX, um escritor romântico da tradição da literatura gótica, com perfil, temas e estilo definidos, e até mesmo com foto publicada em jornais. O heterônimo permitia que o grupo de Aluísio ocupasse ao mesmo tempo espaços variados do campo literário, numa dispersão que foi mal compreendida pela tradição crítica, e até mesmo, como vimos, escamoteada pelos próprios escritores. Entretanto, se redimensionado como autor de uma prática legítima de prosa de ficção, Victor Leal falaria de uma modernidade raramente associada ao grupo e ao romance-folhetim.

\section{REFERÊNCIAS BIBLIOGRÁFICAS}

AZEVEDO, Aluísio. Prefácio de A mortalha de Alzira. In: BILAC, Olavo; MALLET, Pardal. O esqueleto. Mistério na casa de Bragança. Rio de Janeiro: Casa da Palavra, 2000.

BILAC, Olavo. Crônica livre. In: ___ MALLET, Pardal. O esqueleto. Mistério na casa de Bragança. Rio de Janeiro: Casa da Palavra, 2000.

; MALLET, Pardal. O esqueleto. Mistério na casa de Bragança. Rio de Janeiro: Casa da Palavra, 2000.

BROCA, Brito. Aluísio Azevedo e o romance folhetim. In: BILAC, Olavo; MALLET, Pardal. O esqueleto. Mistério na casa de Bragança. Rio de Janeiro: Casa da Palavra, 2000.

DU TERRAIL, Ponson. As aventuras de Rocambole. Rio de Janeiro: Nova Fronteira, 1977.

ECO, Umberto. Obra aberta. São Paulo: Perspectiva, 2001. 
MÉRIAN, Jean-Yves. Aluísio Azevedo: vida e obra. Rio de Janeiro: Espaço e Tempo, 1988.

MEYER, Marlyse. Folhetim: uma história. São Paulo: Cia. das Letras, 1996.

. As mil faces de um herói canalha. In:

As mil faces de um herói canalha e outros ensaios. Rio de Janeiro: UFRJ, 1998.

TINHORÃO, José Ramos. Os romances em folhetim no Brasil: 1830 à atualidade. São Paulo: Duas Cidades, 1994.

THOMASSEAU, Jean-Marie. Melodrama. São Paulo: Perspectiva. 2005. 